\title{
Traceability of sediment analysis
}

\author{
U. Förstner
}

Chemical analysis of sediments provides an efficient tool for water-quality management. A basic sequence of measurements comprises three steps: sampling and sample preparation; grain size as a characteristic sediment feature; and, analytical procedures based on standardized extraction schemes and reference materials. These can be considered as an unbroken chain of comparisons. Further steps are split with regard to specific purposes: sediment-quality assessment, including biological effects; coupling of sediment-quality data with erosion-risk evaluation; chemical changes following resuspension of anoxic sediments; and, modeling of chemical sediment data. In the light of the economic value of these further steps for developing and executing far-reaching management plans, coordinated efforts should be made to improve their traceability (e.g., by organized dissemination of results from on-going research (ageing effects), official documentation of techniques and instruments in a relative new field (erosion effects), extension of standardized extraction schemes (anoxic sediments, capacity-controlling properties), and development of new reference materials (pore water)).

(C) 2004 Elsevier Ltd. All rights reserved.

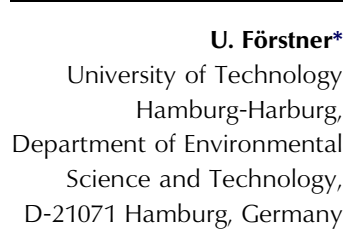

*Tel.: + 49-40-42878-3208;

Fax: + 49-40-42878-2315;

E-mail: u.foerstner@

tu-harburg.de

\section{Introduction}

Sediment is an integral and dynamic part of river basins, including estuaries and coastal zones. Sediment originates from the weathering of minerals and soils upstream and is susceptible to transport downstream by the river water. Flow rates decline in lowland areas where transported material settles along the river banks (sedimentation) and on the bed of the river. At the end of the river, most of the sediment is deposited in the estuary and on the seabed of the coastal zone [1].

In the 1970 s and 1980s, anthropogenic emissions caused a rapid deterioration of sediment quality. In addition, the hydrodynamic conditions of many rivers were altered: directly by the building of hydraulic constructions, such as dykes, dams, sea walls, drainage; and, indirectly by changes in land use, such as deforestation and urbanization. Apart from seasonal flooding of polder areas and flood plains, there have recently been catastrophic cases because of extreme rainfall and the failure of dams; the breakage of tailing dams in highly contaminated areas, such as mining districts of Spain (1999) and Romania (2000), caused considerable immediate hazards.

Remediation techniques for contaminated sediments are generally much more limited than for most other solid waste materials. The widely diverse contamination sources in larger catchment areas usually produce a highly complex mixture of pollutants. For most sediments from maintenance dredging, there are more arguments in favor of disposal than treatment. Geochemical engineering approaches, such as sub-aqueous depots, active capping, and in situ stabilization [2], seem to provide appropriate ways of reducing contaminant release in the surface water and, subsequently, into the food chain.

From a practical viewpoint, four functions of aquatic sediments can be distinguished (and these will be treated separately in Section 7 with respect to the application of the traceability concept in chemical analysis):

- Memory effect, mainly in dated sediment cores from lakes, reservoirs and marine basins, as historical records reflect variations of pollution intensities in a catchment area.

- Life support, i.e. sediment has ecological, social and economic value, as an essential part of the aquatic ecosystem by forming a variety of habitats and environments [1]. A systematic approach is needed, comprising biotests and effect-integrating measurements, because chemical analysis is inefficient in the assessment of complex pollution.

- Secondary source, mobilization of contaminated particles and release of contaminants after natural or artificial resuspension of sediments [3]. 
- Final storage quality, the ability of a sediment body for long-term immobilization of potentially hazardous substances; e.g., this can be achieved by transfer into practically insoluble pollutant species [2].

In the future, remediation methodology as well as the preceding risk assessment will be seen in the context of sustainable sediment management (SSM) and the holistic river-basin approach of the Water Framework Directive (WFD) of the European Union (EU). (However, regarding the immense quantitative and qualitative problems, the role of sediments has not been adequately taken into account in this Directive so far [4]).

The aim of attaining SSM, where the traceability concept should be embedded, is the central strategic objective of SedNet, Demand-Driven European Sediment Research Network [1]. In the description of trends in sediment analysis (Section 7), I pay special attention to SedNet's recommendations for future developments [5]:

- first, short-term priorities, such as standardization of basic tools; and,

- then, medium to long-term (>5 years) needs, such as integration of quality and quantity aspects (e.g., sediment quantity criteria), development of complementary tools, and other issues, such as erosion and the role of organic matter.

\section{New aspects}

\subsection{Combined ecological and chemical risk assessment-river-basin view}

Sediment management, i.e. identification of clean-up options for contaminated sediments, "requires a solid mix of pragmatism and sound science" [6]. In a comprehensive sediment-assessment approach, five basic components should be considered:

1. benthic community structure;

2. laboratory bioassays for evaluating the toxicity of pollutants on-site;

3. bioaccumulation information;

4. knowledge of site stability; and,

5. physico-chemical sediment properties.

Since benthic organisms, in particular, have direct contact with sediment, and the contaminant level in the sediment may have a greater impact on their survival than aqueous concentrations, a paradigm shift has taken place in the priority given to biological data. However, basic biological knowledge requires strong support from other disciplines (e.g., on the potential for mobility over long periods of time, as well as on the bioavailability over a range of sediments, sediment pore waters, organismal microenvironments, and overlying water chemistry ( $\mathrm{pH}$, redox, and hardness)).

Many national assessment schemes are based on a Triad approach [7], combining physico-chemical, biological and ecotoxicological assessment methodologies [8]. In some of these schemes, identical weight is assigned to each of the three assessments; the principle behind the classification of the watercourse sediments rests on an evaluation of the abnormality compared to a reference condition and this creates the possibility of classifying watercourse sediments in the absence of existing biological standards [8].

From the perspective of the WFD, it seems logical to harmonize the biological effects-based assessment (BEBA) approaches at a river-basin level; because the WFD focuses primarily on water quality, it may be expected that priority should be given to in situ BEBA approaches (i.e. to determine whether poor ecological status of waters is caused by sediment contamination [8]).

I will discuss traceability issues of both aspects of sediment risk assessment-combined chemical/biological and river-basin view-in Section 7.2.

\subsection{Erosion risks and pollutant mobility-in situ and river-basin scale}

In the description of dynamic fluvial processes, three scientific disciplines are involved and three objects of study can be distinguished (Fig. 1): suspended matter; sediment; and, pore water or open water. Special targets for study are: formation of aggregates in turbulent water; flocs and biofilms from organic reactions; and, formation of new surfaces for readsorption of dissolved pollutants. The main focus is on the degradation of organic matter, which affects both hydrodynamic processes-here erosion versus sedimentation-and geochemical redox cycles. The crucial question, after all possible interactions between both existing and newly formed solid and dissolved phases, refers to the net release of dissolved oxygen content (DOC), nutrients and pollutants into the open water.

Hydraulic processes form the primary input factors for the large-scale dispersion of contaminants in flood plains, dike foreshores and polder areas. Unlike problems related to conventional polluted sites, the risks here are primarily connected with the deposition of contaminated solids on soils in downstream regions. In the preliminary SedNet recommendations for research priorities related to sediment [5], short-term, soilspecific issues include the fate of sediment-associated contaminants when sediment is deposited upland and a better understanding of the impact on ground water, water and soil ecoystems. Medium/long-term issues related to the EU Soil Strategy (then, presumably, a "Soil Framework Directive") will focus on integrated 


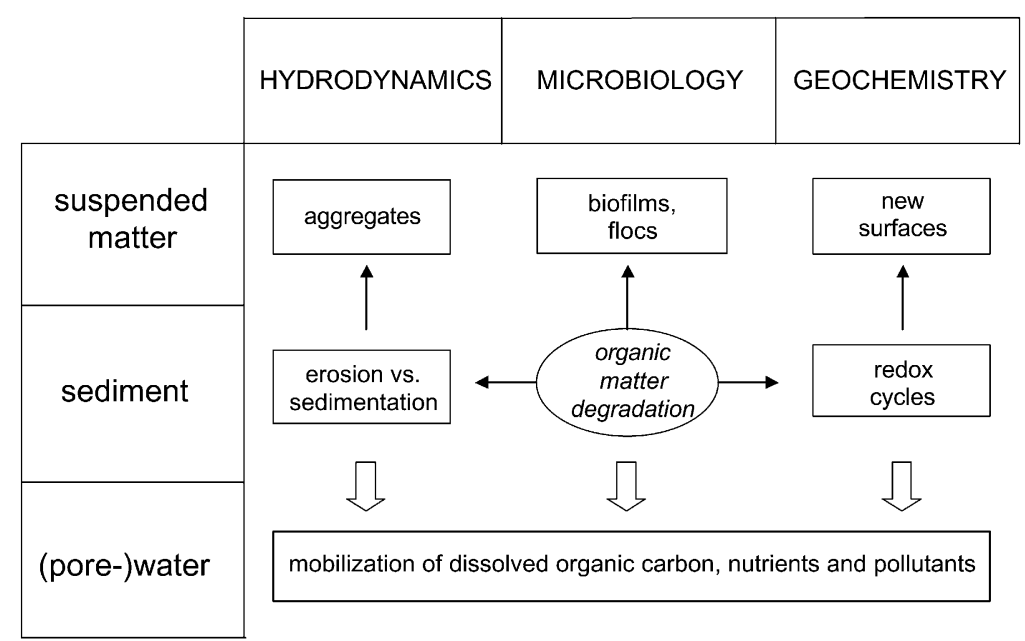

Figure 1. Scientific disciplines and study objectives in a coordinated research program on Fine Sediment Dynamics and Pollutant Mobility in Rivers (SEDYMO [9]).

research to determine the sediment-transport process at the river-basin scale as a function of land and water use and hydrological (climate) change in Europe [5].

A basin-scale framework will comprise two principal levels of decision-making: basin-scale evaluation (site prioritization); and, site-specific assessment (risk ranking). Questions that should be asked during selection of management options include [10]:

1. Is the site erosive or depositional?

2. Will management options change that, and how will that impact other sites?

3. Can sediments coming in be counted on to aid risk reduction, via burial, mixing or attenuation?

4. Does sediment coming in bring new contaminants?

I will discuss traceability issues of both aspects associated with sediment erosion-in situ mobilization of pollutants and transfer/deposition of contaminated sediments in downstream areas-in Section 7.3.

\subsection{Risk reduction by ageing processes}

Initial findings from soil studies were that, as the residence time of compounds, such as phenanthrene and 4nitrophenol, in soil increases, they become increasingly unavailable to microorganisms and resistant to mild extraction [11]. Part of these effects may be related to specific geosorbents, such as combustion residue of particulate carbon (e.g., chars, soot, and ashes) that exhibit typical non-linear, hysteretic sorption behavior for organic and inorganic substances [12]. For inorganic pollutants, mainly heavy metals and arsenic, the effect of ageing mainly comprises enhanced retention via processes such as sorption, precipitation, co-precipitation, occlusion, and incorporation in reservoir minerals.
In practice, non-destructive, "intrinsic" bonding mechanisms and their temporal development have so far found much less recognition compared to destructive processes, such as biological degradation [13]. Nevertheless, these so-called "diagenetic" effects, which, apart from chemical processes, involve an enhanced mechanical consolidation of soil and sediment components by compaction, loss of water and mineral precipitations in the pore space, may induce an essential reduction in the reactivity of solid matrices.

Natural attenuation and ageing effects will characteristically influence the use of equilibrium partitioning models in developing sediment quality criteria (SQC) from final chronic water quality criteria. The example in Fig. 2 [14] indicates that the SQC of 1,4dichlorobenzene would be nearly two orders of magnitude less strict when the process of irreversible adsorption on the resistant fraction in sediment is taken into account.

Several chemical and physical methods have been considered as ways of measuring the bioavailability of organic compounds in soil, and the results of analysis by such procedures have been correlated with bioavailability to earthworms, springtails, nematodes, and microorganisms (review by Alexander [15]). Solidphase microextraction (SPME) presents a very promising technique for determining bioavailable concentrations of hydrophobic chemicals in aquatic environments [16]. Characterization of long-term reactivity and bioavailability of heavy metals in sediments can be performed using molecular-scale techniques on metal hydroxide surface precipitates [17] and by microbial biosensors [18]. Particularly promising in predicting kinetically-labile solid phases of metals is the technique of diffuse gradients in thin films (DGT [19]). 


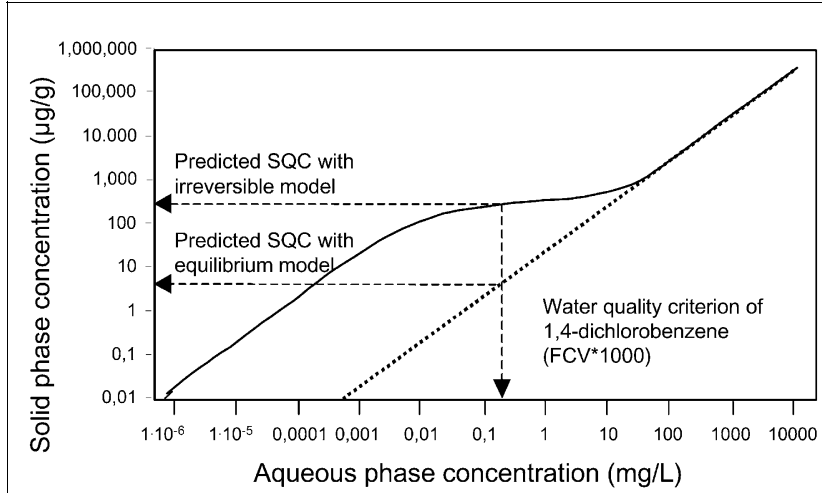

Figure 2. Implications of irreversible adsorption for sediment quality criteria (SQC) (after [14]).

The methodologies developed in the framework of the ageing concept will influence the traceability aspects in the field of ecological/chemical risk assessment (Section 7.2) and in relation to erosion stability/pollutant mobility both in situ and river-basin wide (Section 7.3), and the decision-making process for remediation techniques (Section 7.4).

\section{Sediment sampling and sample preparation}

Monitoring of sediment contaminants and assessment of sediment quality are usually carried out with the objectives of determining the extent to which the sediments are either a source or a sink for contaminants and evaluating the effects of these contaminants on the environment of the investigated water body. Such studies can either have regulatory implications, such as dredging and disposal of the dredged material and remediation of the contaminated area, or be carried out to assess risk to human and environmental health through research of different sediment/water interaction processes [20].

A long-term program of sediment studies will normally comprise a series of objectives of increasing complexity, each drawing part of its information from the preceding database; a typical sequence of objectives may be illustrated as follows, though not all may be required to complete a program [21]:

1. Preliminary site characterization-Low-density sampling with limited analytical requirements, to provide a general characterization of an area for which little or no previous information exists.

2. Identify anomalies-More detailed sampling and analysis, designed to establish the presence and extent of anomalies.

3. Establish references-To create reference points in the form of some measured parameters for future comparison.
4. Identify time changes-To show trends and variations of sediment data over time, by using sediment cores or other repeated sediment samplings.

5. Calculate mass balances-To account for the addition and subtraction of sediment-related components within an aquatic environment (a complex study), by means of accurate and representative sampling and analysis.

6. Process studies-Specialized sampling to improve state of knowledge about aquatic systems (e.g., by supplementary laboratory experiments).

\subsection{Sampling}

According to Hakanson and Jansson [22], as many as 12 different factors might influence the informative value of the sediment samples: type of water system; prevailing bottom dynamics; size of the water body; bottom roughness; anthropogenic factors; sediment chemical conditions; sediment physical and biological characteristics; number of samples; type of sampling net; sampling devices; sample handling; and, reliability of laboratory analysis. However, "no systematic study has yet been made which accounts for even half of these 12 factors" [23].

It is generally accepted that fine-grained suspended and bottom-sediment particles (silt and clay with particle size $<63 \mu \mathrm{m}$ ) accumulate greater concentrations of contaminants (particularly those with low water solubility) than coarse particles (particle size $>63 \mu \mathrm{m}$ ). The fine-grained particles exhibit properties suitable for different physico-chemical sorption and ion exchange of contaminants than the coarse particles (see review by Horowitz [24]). Further, fine-grained sediment supports a large part of the benthic community by supplying the food in sediment organic matter associated with the fine-grained particles. The assessment of sediment quality must therefore be carried out on the finegrained sediments sampled in areas of the water body where permanent accumulation of sediments is taking place [20].

3.1.1. Project planning. There are particular items of data that are relevant to project planning, including [25]:

- general information on the watershed, including quantity and quality of run-off, climatic conditions, general or specific land use, types of industries, effluent, and urban run-off;

- distribution, thickness and types of sediments, particularly fine-grained sediments (this will assist in assessing the physical extent of sediment accumulation, zones of deposition and erosion, and sediment transport);

- quantity, particle size, geochemistry, and mineralogy of suspended sediments discharged 
by tributaries, storm-water run-offs or originating from shoreline erosion (knowledge of the nature and quantity of dissolved and particulate materials entering the area is necessary for the calculation of contaminant and nutrient loading);

- horizontal and vertical profiles of physical (e.g., porosity, geotechnical properties, water content, bulk density, and grain size) and chemical (e.g., organic matter content, concentrations of nutrients, and metals and organic contaminants) characteristics of bottom sediments; and,

- biological community structure, composition and diversity, bioaccumulation of contaminants, or bioassay results.

3.1.2. Sampling stations. In some cases, the objectives of a study of sediment will define the location of the sampling stations [20]:

- The objective of a baseline sediment quality survey is to determine sediment quality within a water body at a fixed point in time against which future surveys may be compared.

- The monitoring survey, similar to the baseline survey, involves regular or periodic resampling of sediments. However, the objective of a monitoring survey is to determine the changes in sediment quality over a period of time.

For both baseline and monitoring sediment surveys, the sediments always need to be sampled from areas of permanent accumulation of fine-grained sediments. Horowitz [24] provides some information on four types of very commonly employed sampling programs and their limitations. For complex surveys, there are numerous types of sampling patterns from which to choose (e.g., spot samples, random grids, square grids (including nested and rotated grids), parallel line grids and transverse line grids (with equal or non-equal sampling), and ray grids or concentric arc sampling), and each of which offers some particular advantage [21].

3.1.3. Sampling devices. Corers and bottom samplers are particularly used for fine-grained sediments. An extensive review of devices for bottom-sediment sampling was presented by Mudroch and MacKnight [26]. For source-reconnaissance analysis, fine-to-mediumgrained bottom deposits from a depth of $15-20 \mathrm{~cm}$ can be collected (e.g., with a grab sampler). Material of the upper, flaky, light brown, oxidized layer is generally dissimilar to the layers below it. It is suggested that the chiefly dark layers directly underneath (ca. 1-3 cm depth) are more representative of the pollution situation in the last few years, especially in river deposits exhibiting rapidly fluctuating sedimentation rates, and should be given priority in subsequent investigations. To complement this, surface sediment (current contamination) as well as a sample from deeper sections (10-20 cm depth) could be examined.

In environments with a relatively uniform sedimentation (e.g., in lakes and in marine coastal basins, where the deposits are fine-grained and occur at a rate of 1-5 mm/year), a more favorable procedure involves taking vertical profiles with a gravity or valve corer. A core profile of approximately $1 \mathrm{~m}$ covers a historical period of at least 200 years, and its development can be traced by virtue of the pollutant content in the individual layers.

3.1.4. Pore water [27]. The composition of interstitial waters in sediments is perhaps the most sensitive indicator of the types and the extent of reactions that take place between pollutant-loaded sediment particles and the aqueous phase that contacts them. Interstitial waters are recovered from sediments by leaching, centrifugation or squeezing. Most importantly, oxidation must be prevented during these procedures.

Some conclusions from a SETAC review of toxicity testing of pore water, including recommendations for future areas of research, were as follows [27]:

- Sampling, extraction, and storage techniques are critically important for achieving the most field-representative samples of pore water.

- It is nearly impossible to avoid artifacts and chemical changes when removing pore water from sediment and using it in a toxicity test. Determination of chemical concentrations in pore waters is recommended, in addition to the regular contaminant measurements conducted in the whole sediment, as a means of providing information on routes and levels of exposure, aiding in the interpretation of test results, and identifying sources of toxicity.

- The measurement of several pore-water features, a number of which can act as confounding factors (e.g., salinity, alkalinity, $\mathrm{pH}$, conductivity, DOC, $\mathrm{NH}_{3}, \mathrm{H}_{2} \mathrm{~S}$, and oxidation potential (Eh)), should be recorded shortly after pore-water collection and after storage. This would help in interpreting test results, understanding the contribution of these factors to concordance or discordance between solidphase and pore-water test methods.

\subsection{Handling, preparation and storage of sediment samples}

3.2.1. Measurement and handling of samples in the field. A review by Mudroch and Azcue [20] covered major operations, such as: 
1. measurement of $\mathrm{pH}$ and $\mathrm{Eh}$ (including a detailed description of equipment and solutions used in the measurements);

2. sub-sampling for determination of cation exchange capacity;

3. sub-sampling under oxygen-free atmosphere;

4. sample mixing and sub-sampling into prepared containers; and,

5. sampling hazardous sediments and safety requirements.

3.2.2. Preparation of samples of wet sediment. A general scheme for handling samples for tests and analysis of wet sediments is presented in Fig. 3 [28].

Samples for determination of particle-size distribution should not be frozen but stored at $4{ }^{\circ} \mathrm{C}$. Tightly sealed plastic bags, glass jars, or other containers can be used to store samples prior to particle-size analysis. Sediments with a high iron content should be stored in air-tight containers to avoid precipitation of iron oxides on particle surfaces and should be analyzed as soon as possible after collection.

Sediment samples for geotechnical studies can be stored for several months at $4^{\circ} \mathrm{C}$ in a humidity-controlled room, without any large changes in sediment properties. Long cores, such as those collected by piston coring, can be cut into lengths suitable for storage, wrapped to preserve their original consistency, and stored in a refrigerated room.

Freezing has long been an acceptable preservation method for sediments collected for the determination of organic and inorganic constituents. It has been shown that rapid deep-freezing can best maintain sample integrity and thus enable investigation for concentrations of contaminants. The lower the temperature of deep-freezing the better; $\sim 80^{\circ} \mathrm{C}$ is the suggested maximum.

Samples collected for investigations of benthic organisms are usually processed in the field by wet sieving through different size sieves. If, for any reason, the samples cannot be processed in the field, they should be stored at $4^{\circ} \mathrm{C}$ in the dark and processed in the laboratory as soon as possible.

\subsubsection{Preparation of samples of dry sediment. Handling} operations of dry sediments include drying, sieving, grinding, mixing, and homogenization. Three types of drying are commonly used to prepare solid samples prior to analysis [28]:

- Air-drying is rarely used for the preparation of sediments for pollution studies, since it may generate undesirable changes in sediment properties (e.g., changes in metal availability and complexation were shown for samples that were air-dried). In some cases, air-drying has been used to avoid losses of components, such as mercury, which are volatile at temperatures above $50-60^{\circ} \mathrm{C}$.

- Oven-drying of sediments is usually carried out on samples collected for the determination of inorganic components, such as major and trace elements. Oven-drying is not acceptable for sediments that contain any volatile or oxidizable components, whether they be organic or inorganic, and may contribute to the alteration of even non-volatile organics.

- Freeze-drying can be used for drying sediments collected for the determination of most organic pollutants as well as for analysis of inorganic components, such as the major and trace

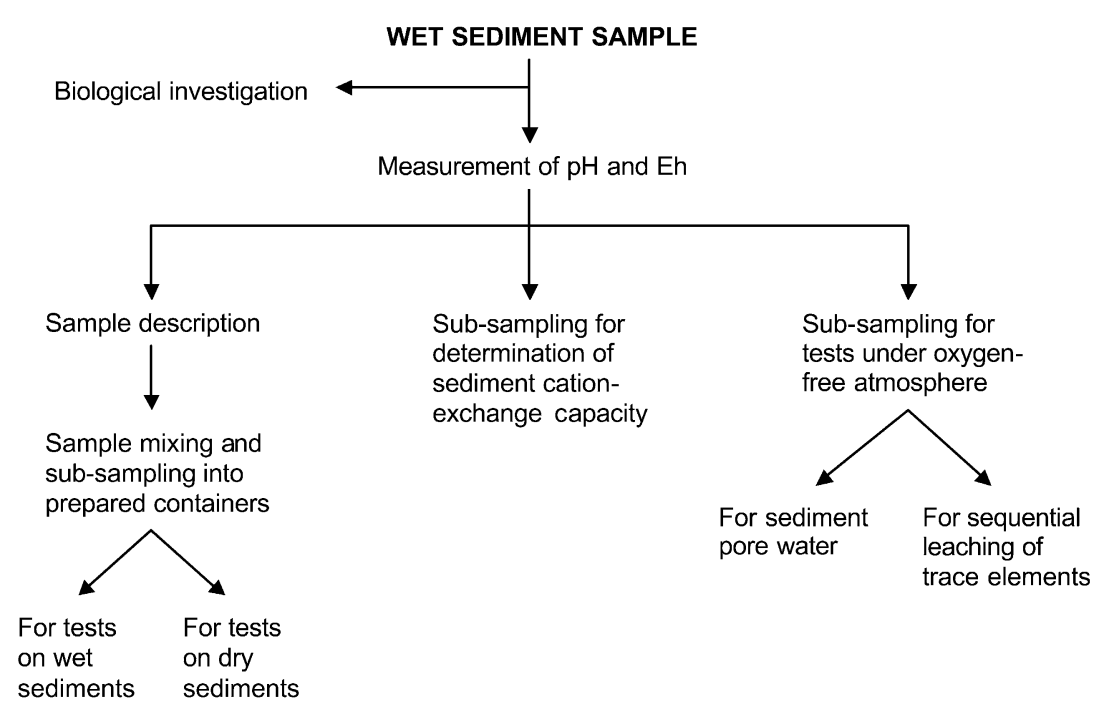

Figure 3. Handling samples for tests and analyses of wet sediments (after [28]). 
elements. The principal advantages of freezedrying for sediments are:

(i) low temperatures avoid chemical changes in labile components;

(ii) loss of volatile constituents, including certain organic compounds, is minimized;

(iii) most particles of dried sediments remain dispersed;

(iv) aggregation of the particles is minimized;

(v) sterility is maintained; and,

(vi) oxidation of various minerals or organic compounds is minimized or eliminated

3.2.4. Anoxic sediment treatment. Anoxic sediment samples require different sample-preservation techniques, such as oxygen exclusion. Drying and freezing (also freeze-drying) of the samples should be avoided for material designated for extraction procedures. If total analysis or strong acid digestion is planned, the sediment is dried at $60^{\circ} \mathrm{C}$, crushed and stored; for mass calculations, reweighing after drying at $105^{\circ} \mathrm{C}$ may become necessary. For a more differentiated approach, in particular for solid speciation studies on anaerobic samples, the following pre-treatment scheme was developed [29]:

- Samples were taken immediately from the center of the material (collected with a grab or corer) with a polyethylene spoon, and filled into a polyethylene bottle up to the surface.

- Immediately after arriving at the laboratory, sediments were inserted into a glove box prepared with an inert argon atmosphere. Oxygenfree conditions in the glove box were maintained by purging continuously with argon under slight positive pressure.

- Extractants were deaerated prior to the treatment procedure.

3.2.5. Quality control (sediment and pore water). Containers and other equipment used in handling sediment samples after retrieval can be a significant source of contamination [20] (e.g., plastics contain plasticizers that can be potential contaminants in the determination of organic compounds). Glass, porcelain, stainless steel, Teflon, or Teflon-coated instruments should be used in handling sediment samples to be analyzed for organic components. Wide-mouth amber or clear glass jars and bottles with aluminum foil or Teflon-lined caps are the best containers, but certain compounds (e.g., phenols) can adsorb to these surfaces.

Metal containers, spoons, or other equipment may contaminate samples that will be analyzed for metals and trace elements. If both organic and metal analysis are required for a given sediment sample, a Teflon container is recommended.
Since standard sampling and preparation techniques are not available for sediments, results from sediment analysis and, in particular, their application for SQC, depend in a special way from a high level of quality control $(\mathrm{QC})$ and quality assurance $(\mathrm{QA})$ both in field and laboratory [30]. QC in planning includes choice of: (i) sampling locations; (ii) sampling procedures; and, (iii) material. QC in field sampling covers: (i) sample collection; (ii) sample handling; (iii) cleaning procedures; (iv) transport; (v) preservation; and, (vi) storage.

Two techniques can be used for $\mathrm{QC}$ in sediment sampling [20]:

- Collection of more than one sediment sample at selected sampling sites using identical sampling equipment, such as multicorers, as well as using identical field sub-sampling procedures, handling and storage of the samples, and methods for sediment analysis.

- Sub-division of the collected sample into a few sub-samples and treatment of each sub-sample as an individual sample. The results of chemical analysis of all sub-samples indicate the variability because of sampling and analytical techniques and sediment heterogeneity within a single collected sample.

The control samples used in sediment studies include sampling, transport, and sampling equipment, and control samples for laboratory procedures. Contrary to water sampling, sediment sampling generally does not require the use of blanks. However, there are several types of blanks commonly used in sediment pore-water sampling [20]:

- Field blanks are samples of laboratory reagents or reference materials that are carried to the field and exposed to the same procedures (such as transfer into containers, and field physicochemical measurement) as the actual samples.

- Transport blanks are samples free of contamination that are transported from the laboratory to the field and back to the laboratory without being opened. This kind of blank is important when the sample is stored for several weeks prior to analysis.

- Equipment blanks are samples of water that have been used to rinse the sampling equipment. These blanks are critical when sampling sediment pore waters, and they are collected before and after cleaning the sediment pore-water sampling devices.

- Spiked samples in the field are samples to which a known amount of a certain element or compound of interest is added in the field. These samples are used to identify possible 
interferences of complex matrices, or timerelated losses by volatilization.

\section{Correction for grain size}

Grain size is one of the most significant factors controlling both suspended and bottom-sediment capacity for concentrating and retaining organic and inorganic contaminants (e.g., there is a very strong positive correlation between decreasing grain size and increasing trace element concentration (see review by Horowitz [24])). This correlation results from a combination of both physical (e.g., surface area) and chemical (e.g., geochemical substrates) factors. However, in many instances, it is impossible to differentiate between effects caused by factors such as surface area, cation exchange capacity, surface charge, and the increasing concentration of various geochemical substrates and effects because of grain size.

A large number of sediment analyses, which have been performed for the inventory, monitoring and surveillance of pollution in aquatic systems have clearly shown that it is imperative, particularly for river sediments, to base their data on a standardized procedure with regard to particle size (review by Förstner [31]). The methods will mostly reduce (not eliminate!) the fraction of the sediment that is largely chemically inert (i.e. mostly the coarse-grained, feldspar and carbonate minerals) and increase the substances active in pollutant enrichment (i.e. hydrates, sulfides, amorphous and fine-grained organic materials).

\subsection{Separation}

Separation of grain size is advantageous because only few samples from a particular locality are needed. However, it has been inferred that the decrease of pollutant concentrations in the medium grain-size range should be even more pronounced if mechanical fractionation would more accurately separate individual particles according to their grain size. One has to consider that coatings (e.g., iron/manganese oxides, carbonates and organic substances) on relatively inert material in respect to sorption act as substrates of pollutants in coarser grain-size fractions. Nonetheless, the fraction $<63 \mu \mathrm{m}$ has been recommended for the following reasons [32]:

- pollutants have been found to be present mainly on clay/silt particles;

- this fraction is nearly equivalent to the material carried in suspension-by far the most important transport mode;

- generally sieving does not alter pollutant concentrations (for metals even wet sieving, when water of the same system is used); and,
- numerous pollutant studies, especially with respect to heavy metals, have already been performed on the $<63-\mu \mathrm{m}$ fraction, allowing better comparison of results.

However, it has been argued by Ackermann [33] that separation of fraction $<20 \mu \mathrm{m}$, which can also be performed with nylon sieves, should be favored at least for coastal sediments, where correlation with conservative elements has been found to be better with this fraction than with fraction $<63 \mu \mathrm{m}$ (see below). Also for organic pollutants, separation of fraction $<20 \mu \mathrm{m}$ seem to compare favorably with other grain-size fractions [34].

\subsection{Extrapolation}

Extrapolation techniques for both grain size and specific surface area require a relative large number of samples (10-15). Further complicating matters is the fact that calculation of the regression line is a tedious, mostly inaccurate procedure. The quartz-correction method involves fusion with potassium pyrosulfate that preferentially removes the layered silicates (clay), organic and inorganic carbon and sulfides with a residue made up of quartz plus feldspar and resistant heavy minerals, such as zircone [35]. Extraction of environmentally active trace metals should consider the more mobile fractions of elements, which are introduced by human activities and bound to the sediment in sorbed, precipitated or co-precipitated, or organically complexed form.

Five types of elements were distinguished according to their distribution in sediment cores from Lake Erie [36]:

(i) diagenetically mobile elements. such as iron, manganese and sulfur;

(ii) carbonate elements, carbonate- $\mathrm{C}$ and calcium;

(iii) nutrient elements, organic carbon, nitrogen and phosphorous;

(iv) enriched elements, such as copper, cadmium, zinc, lead, and mercury; and,

(v) conservative elements, e.g. silicon, potassium, titanium, sodium and magnesium.

Comparison of group (iv) elements of environment concern with "conservative" elements (v) seem to be particularly useful for the reduction of grain-size effects, since no separation step is required.

\subsection{Geochemical substrates versus grain size}

Grain size typically influences the concentrations of contaminants, since most surface-active sediment components are enriched in the fine-grained fractions. The relative capacity of collectors (e.g., for trace elements) was arranged by Horowitz and Elrick [37] in the 
following sequence: amorphous iron oxide >total extractable iron $>$ total organic carbon $>$ reactive iron $>$ clay minerals $>$ total extractable manganese $>$ manganese oxides. This relatively simple picture is complicated by the fact that, e.g., aquatic organic matter exists in two physical forms: surface coatings that tend to concentrate in the finer size fractions; and, separate particles that tend to be associated with the coarser size fractions [24]. The major role of clay minerals is not direct sorption of trace elements but rather acting as mechanical substrates for precipitation and flocculation of organic matter and secondary minerals (e.g., hydrous iron and manganese oxides).

\section{Assessment of metal mobility and bioavailability in sediments}

\subsection{Direct trace-element speciation}

Speciation encompasses both chemical and physical forms that an element takes in a geochemical setting. A detailed definition of speciation includes the following components:

1. the identity of the contaminant of concern or interest;

2. the oxidation state of the contaminant;

3. associations and complexes to solids and dissolved species (surface complexes, metal-ligand bonds, surface precipitates); and,

4. the molecular geometry and coordination environment of the metal [38].

The most frequently used technique in the application of synchrotron light sources to address environmental issues has been XAFS (X-ray absorption fine structure spectroscopy), a general term encompassing several energies around an absorption edge for the specific element, namely the pre-edge, near-edge (XANES), and extended portion (EXAFS). EXAFS can provide the identity of the ligands surrounding the target element, specific bond distances, and the coordination number of first-shell and second-shell ligands. Given the intensity of synchrotron facilities, this technique has a detection limit down to $50 \mathrm{ppm}$ [39].

In the study of Zn-contaminated soil [40], XRD (X-ray diffraction) and (electron microprobe analysis (EMPA) as expected- revealed little in terms of the $\mathrm{Zn}$ species in the soil, as the majority of $\mathrm{Zn}$ was not in a detectable form or below the detection limit of the instrument. However, EXAFS provided information that allowed quantification of franklinite $\left(\mathrm{ZnFe}_{2} \mathrm{O}_{4}\right)$, sphalerite $(\mathrm{ZnS})$ and aqueous $\mathrm{Zn}^{2+}$. One of the most important findings was the discovery of artifacts from the use of sequential extractions, as determined by EXAFS; since the neoformed phase was amorphous, most traditional analytical techniques would have been unable to detect it [40].

\subsection{Single and sequential extraction}

Solvent leaching-apart from the characterization of the reactivity of specific metals- can provide information on the behavior of pollutants under typical environmental conditions. Single-extractant procedures are restricted with regard to prediction of long-term effects (e.g., of highly contaminated dredged materials), since these concepts involve neither mechanistic nor kinetic considerations and, therefore, do not allow calculations of release periods. This restriction can be avoided by significant controlled intensification of the relevant parameters ( $\mathrm{pH}$ value, redox potential and temperature), combined with extrapolation on the potentially mobilizable "pools" that are estimated from sequential chemical extraction before and after treatment of the solid material. Kersten gives an overview of the mechanisms of metal mobility after deposition, and methodologies for measuring release rates as well as on leaching processes and procedures [41].

Several aspects of metal partitioning in sediments by leaching/extraction were reviewed by Förstner [42]:

- Because of the instability of polluted solid materials, sample handling and storage prior to analysis are problematic. In particular, changes from reducing to oxidizing conditions, which involve transformations of sulfides and a shift to more acid conditions, increase the mobility of critical metals.

- Simple "standard" leaching tests can be used for easily soluble components, such as halides or sulfates, but, in most cases, they are not adequate for assessing mobility of trace metals. With sequential extraction procedures, rearrangements of specific solid "phases" can be evaluated prior to their actual mobilization.

- Partitioning studies on materials from core profiles are particularly useful, since they provide information on relative variations of elemental phases, irrespective of the method applied, and thereby provide an insight into diagenetic processes taking place after deposition of the sediment components.

- The leachable fraction does not necessarily correspond to the amount available to biota. Studies on the prediction of the trace metal levels in benthic organisms have shown that the prognostic value of sequential extraction data is improved when the trace metal concentrations are normalized with respect to the iron (hydrous oxide) and/or organic content of the sediments [45]. 
Table 1. Three-step sequential extraction procedure for a sediment trial (initial BCR sequence; [44])

Step $10.5 \mathrm{~g}$ sediment extracted for $5 \mathrm{~h}$ with $20 \mathrm{ml}$ of acetic acid $0.11 \mathrm{~mol} / \mathrm{l}$, centrifuged and supernatant decanted for analysis by atomic absorption spectroscopy (AAS) or inductively coupled plasma optical emission spectroscopy (ICP-OES)

Step 2 Residue from step 1 extracted overnight $\left(16 \mathrm{~h}\right.$ ) with $20 \mathrm{ml}$ of hydroxylammonium chloride $\left(\mathrm{NH}_{2} \mathrm{OH} \cdot \mathrm{HCl} 0.1 \mathrm{~mol} / \mathrm{l}\right)$ acidified with nitric acid to $\mathrm{pH} 2$, centrifuged and the supernatant decanted for analysis

Step 3 Residue from step 2 treated twice with $10 \mathrm{ml}$ of hydrogen peroxide $(8.8 \mathrm{~mol} / \mathrm{l})$ and the dry residue extracted overnight with $50 \mathrm{ml}$ of ammonium acetate $(1 \mathrm{~mol} / \mathrm{l})$ adjusted to $\mathrm{pH} 5$ with acetic acid. The supernatant, separated by centrifugation, is retained for analysis

In a series of investigations and collaborative studies, initiated by the Community Bureau of Reference (BCR) of the European Commission (EC), both single extractant and sequential extraction procedures were subjected to interlaboratory trials [44]. For these trials, a simple three-step extraction procedure was used (Table 1; see section 6).

\subsection{Capacity-controlling properties}

Both $\mathrm{pH}$ and redox potential in sediment/water systems are significant parameters for mobilization and transformation of metals. Many investigations have shown that $\mathrm{pH}$ decreases during oxidation of sediments and this process will significantly mobilize toxic metals. Criteria for prognosis of the middle-term and long-term behavior of metals should, therefore, include the abilities of sediment matrices for producing acidity and for neutralizing such acid constituents.

Effects of redox processes on acid-producing potential (APP) and metal mobility in sediments were reviewed by Hong et al. [45]. S, Fe, and $\mathrm{N}$ are the most important elements in redox processes of a sediment/water system. This is because of not only their chemical reactivity, but also their abundance in natural waters and sediments.

The APP concept has been used in the prediction and calculation of acid mine drainage and waste tailing management [46]. Experimental approaches for calculating APP and acid-consuming capacity (ACC) for sulfidic mining residues were summarized by Ferguson and Erickson [47]. A test described by Sobek et al. [48] involves the analysis of total pyritic sulfur; potential acidity is then subtracted from neutralizing potential that can be obtained by adding a known amount of $\mathrm{HCl}$, heating the sample and titrating with standardized $\mathrm{NaOH}$ to $\mathrm{pH}$ 7. Bruynesteyn and Hackl [49] calculated APP from total sulfur analysis; here, ACP was then subtracted from ACC, obtained by titration with standardized sulfuric acid to $\mathrm{pH} 3.5$.

For determining the maximum APP in anoxic sediments, both the FeS pool (actual APP) and the maximum ferrous sulfide (worst case: pyrite) producing potential upon disposal have to be taken into consideration. The latter is expressed by the sulfide-binding capacity, which can be predicted from the reactive metal concentrations- predominantly reducible $\mathrm{Fe}^{3+}$ - available to form sulfide minerals (available sulfide capacity [ASC]).

As demonstrated from an example of Hamburg Harbor mud [50], simultaneous application of standard sequential leaching techniques (BCR version, Table 2) on critical trace metals and matrix components can be used for geochemical characterization of anoxic, sulfide-bearing sediments in relation to the mobility of these metals. In Table 2, the ASC value was calculated from the Fe concentration in Step 2 of the sequential leaching results. The stoichiometry of the oxidizable $S$ fraction and Fe-fraction of Step 3 indicates that the ferrous sulfide extracted in this step was in the FeS form. The sum of both ASC and actual APP gives the maximum APP for the sample, as shown in Table 2. The ACC value for the sample was more simply determined from the Ca concentration released from reactive carbonates by the Na-acetate solution of Step 1, which has to be multiplied by a factor of 0.5 to account for the stoichiometric ratio between pyrite and calcite within the redox reaction. The negative balance between the APP and ACC indicated that the mud sample from Hamburg Harbor has a significant acidification potential.

\subsection{Limiting bioavailability (extractable metal/acid volatile sulfide)}

One of the major chemical components that controls metal activities in the interstitial water of anoxic sediments is acid volatile sulfide (AVS). AVS is operationally defined as the sulfides that are liberated from a sediment sample to which acid has been added at room temperature under anoxic conditions. This operational

Table 2. Balance between APP (acid-producing potential) and ACC (acid-consuming capacity) values for an anoxic sediment sample from Hamburg Harbor [50]. For definitions of Steps 1, 2, and 3 see Table 1

\begin{tabular}{|llll|}
\hline Compound & Function & Value & $\begin{array}{l}\text { Parameter } \\
(\mathbf{m m o l} / \mathbf{k g})\end{array}$ \\
\hline $\begin{array}{llll}\text { Ca in Step 1 } \\
\text { Fe in Step 2 }\end{array}$ & Base potential & $(\times 0.5=)$ & ACC 90 \\
$\begin{array}{l}\text { S in Step 3 } \\
\text { Balance }\end{array}$ & Sulfide sulfur & $(+85)=)$ & max. APP 420 \\
& & & ACC- APP $=-330$ \\
\hline
\end{tabular}


definition includes most of the amorphous and moderately crystalline monosulfides (e.g., FeS) and lesser percentages of other sulfides. A closely related term is simultaneously extractable metals (SEMs), which can be operationally defined as "metals .... [that] form less soluble sulfides than Fe or $\mathrm{Mn}$ and [that] are at least partially soluble under the same test conditions in which the AVS content of the sediment is determined" [51]. The chemical basis for the primacy of the sediment sulfide phase for metal binding is assumed to be that, at equilibrium, $\mathrm{S}^{2-}$ successfully out-competes all other common dissolved or particle-associated ligands for metal ions and forms insoluble metal sulfides [52].

It has been suggested that, if the molar concentration of AVS that is extracted from a sediment exceeds the molar sum of the simultaneously extracted metals ( $\Sigma$ SEM) that form more insoluble sulfides than iron sulfide (i.e. NiS, $\mathrm{ZnS}, \mathrm{CdS}, \mathrm{PbS}$, and $\mathrm{CuS}$, any one of which is denoted by MS), then those sediment metals should not be toxic to sediment-dwelling organisms $[53,54]$.

There are several concerns about using the SSEM/ AVS ratio, the most important being that, in an established sediment, the biota create microenvironments in which the chemistry differs from the bulk sediment [55]. Burrowing organisms, which occur more commonly in marine systems than in freshwaters, pump oxic water into their burrows, causing a localized high redox potential that affects the local concentrations of AVS and trace metals, regardless of the bulk content of AVS in the surrounding sediment.

Griscom et al. [56] evaluated geochemical influences on assimilation of sediment-bound metals in a series of experiments using suspension-feeding mussel Mytilus edulis and facultative deposit feeder Macoma balthica. The results imply that:

- metals associated with sulfides and anoxic sediments are bioavailable;

- the bioavailability of metals from sediments decreases over exposure time;

- organic carbon content generally has a small effect on assimilation efficiencies (AEs); and,

- AEs of sediment-bound metals differ among species [56].

\section{Standardization of extraction procedures for sediment analysis}

In most practical applications, chemical analysis of soils and sediments aim to assess potential adverse effects on biota and, in this context, the bioavailable forms of pollutants deserve particular attention. The development and the application of extraction schemes started at the end of the 1970s and the EC (through the BCR Program and its successors) has been the only organization to try systematically to evaluate the comparability of data obtained from various schemes and different laboratories (through the organization of interlaboratory studies) and to propose harmonization of the most frequently used approach [57]. Among other things, this resulted in the production of Certified Reference Materials (CRMs) for extractable heavy metals and phosphorous forms in soils and sediments. Even if the schemes are not standardized sensu stricto (i.e. they were not adopted as official standards by an international standardization organization), they fulfill the same role in enabling data comparability in this analytical field [58].

\subsection{Three-step sequential extraction scheme for heavy metals [61]}

In 1987, the BCR Program started a series of investigations and collaborative studies with the aim of harmonizing and improving the methodology for sequential extraction determination of trace metals in sediments. In 1992, a group of European experts proposed a threestep sequential extraction procedure (see Table 1).

Two river sediments were selected for an intercomparison exercise involving 20 laboratories. The first certification campaign was undertaken with a lake sediment collected from different sampling sites of Lago Maggiore (Italy) under the responsibility of the Environment Institute of the Joint Research Center (JRC) in Ispra (Italy). The homogeneity and stability studies carried out with this sediment material corroborated the feasibility studies on the possibility of certifying the amount of extractable metal following the standardized sequential extraction procedure. Extractable contents of $\mathrm{Cd}, \mathrm{Cr}, \mathrm{Ni}, \mathrm{Pb}$ and $\mathrm{Zn}$ were certified in the first step of the procedure, $\mathrm{Cd}, \mathrm{Ni}$ and $\mathrm{Zn}$ in the second step, and $\mathrm{Cd}, \mathrm{Ni}$ and $\mathrm{Pb}$ in the third step; $\mathrm{Cu}$ in the first step and $\mathrm{Pb}$ in the second step were given as indicative values.

BCR CRM 601 was the first available tool for the validation of methodology in the sequential extraction research field; a systematic study to assess the sources of uncertainty was carried out, focusing mainly on the second step of the sequential extraction procedure [60].

A new sediment material, BCR CRM 701, taken from Lake Orta (Piemonte, Italy), was prepared in the Environment Institute of the JRC in Ispra following the validated procedure used for the preparation of BCR CRM 601 [59]. The material was certified in an intercertification campaign for extractable contents of $\mathrm{Cd}$, $\mathrm{Cu}, \mathrm{Cr}, \mathrm{Ni}, \mathrm{Pb}$ and $\mathrm{Zn}$ in the three steps of a modified BCR scheme [60] and it has been available for purchase from the Institute for Reference Materials and Measurements (IRMM) since the beginning of 2001 [61]. 


\subsection{Phosphorus sequential extraction in fresh water sediments [62]}

Since phosphorus is regarded as a key factor responsible for the eutrophication of fresh water, and because not all forms of phosphorus are bioavailable, the EC through the Standards, Measurements and Testing program has launched a collaborative project similar to that for metals (Section 6.1) that aimed to:

1. design a harmonized sequential extraction scheme;

2. test the selected scheme in interlaboratory studies involving expert European laboratories; and,

3. certify the extractable phosphorus content of a sediment reference material.

The harmonized extraction sequence is based on the Williams scheme [63], differentiating $\mathrm{NaOH}-$ extractable $\mathrm{P}$ ( $\mathrm{P}$ bound to $\mathrm{Al}, \mathrm{Fe}, \mathrm{Mn}$ oxides or hydroxide, $\mathrm{HCl}-$ extractable $\mathrm{P}$ (Ca-bound $\mathrm{P}$ ), organic $\mathrm{P}$, inorganic $\mathrm{P}$, and concentrated $\mathrm{HCl}-\mathrm{P}$ (total P). Interlaboratory studies were performed in the period of 1997-2000 [62]. CRM 684 has been available from the IRMM (http:// www.irmm.jrc.be/mrm.html) [64].

\section{Sediment functions}

\subsection{Surveillance investigations ("memory effect")}

Analysis of stream sediment has long been standard practice in mineral exploration [65]; by more extensive sampling and analysis of metal contents in water, soils and plants, the presumable enrichment zones can be narrowed down and, in favorable cases, localized as exploitable deposits. On a qualitative basis, sediment analysis can be used to estimate point sources of pollutants that, upon being discharged to surface waters, do not remain in solution but are rapidly adsorbed by particulate matter, thereby escaping detection by water monitoring [66].

Surveillance is a "continuous specific observation and measurement relative to control and management" [67]; the primary objective is to trace and observe sources and pathways of specified hazardous substances [68]. If one simple aim of a study is to determine the presence or absence of a specific contaminant in bottom sediment at a given area, then the sediment can be sampled at one or a few sampling stations at fine-grained sediment deposition sites. However, after confirmation of the presence of the contaminant in the sediment, the study may be expanded to determine the extent of sediment contamination by the specific compound or element with the area, the sources of the contaminant, the history of the loading of the contaminant, its transport, bioaccumulation, and so on [20].
For surveillance purposes, dry samples are normally used (Section 3.2.3). Normalization with respect to granulometry is crucial. Generally, a correction for sediment grain size after chemical analysis is preferred, since, during sieving, internal grain size inhomogeneities would persist. This becomes clear when the results of separating the fine fractions from a sandy sediment and a clayey sediment are compared: for the sandy sediment sample, the separated (sieved) particles will be close to the borderline grain size; and, for a clayey sediment sample, the grain-size distribution is not influenced much by the sieving process (rather shifting to the more fine-grained part of the spectrum). According to a proposal of O'Connor [69], the concentration data of contaminants in different bulk samples can easily be compared by dividing them by the percentage of the fraction $<20 \mu \mathrm{m}$ or $<63 \mu \mathrm{m}$, respectively, of the sediment sample; this simple comparison is possible if the sediment contains more than $20-30 \%$ of these fractions.

Use of reference elements is the most common approach to normalizing concentrations of particleassociated chemicals with respect to grain size. In the case of sediments, elements that are typical constituents of the fine-grained fractions, mainly clay minerals, are of primary interest. Table 3 summarizes the correlation coefficient, " $r$ ", between the contents of such elements ("conservative" elements, see Section 4.2 ) and the percentage $<20 \mu \mathrm{m}$ and $<63 \mu \mathrm{m}$, respectively, as determined from more than 100 sediment samples from the estuary of the Ems river in Northern Germany [33]. According to Table 3, cesium appears to be the preferred reference element for two reasons: it is particularly well correlated $(\mathrm{r}=0.987)$ with the percentage of the $<20 \mu \mathrm{m}$ fraction; and, $\mathrm{s}(100 \%) / \mathrm{s}(0 \%)$ is greater than for the other elements.

7.1.1. Traceability. For the given purpose, namely to detect anomalies and to trace typical sources of pollution ("hot spots"), the standard scheme from "sampling", "sample preparation" (with particular emphasis on grain-size correction), "chemical analysis" (use of dry bulk sediment reference material) to the "interpretation of results" does not involve major

\begin{tabular}{|c|c|c|c|c|}
\hline & Cs & Sc & $\mathrm{Fe}$ & $\mathbf{R b}$ \\
\hline \multicolumn{5}{|l|}{ Fraction $<20 \mu \mathrm{m}$} \\
\hline $\mathrm{r}$ & 0.987 & 0.982 & 0.858 & 0.958 \\
\hline $\mathrm{s}(100 \%) / \mathrm{s}(0 \%)$ & 14.0 & 7.3 & 6.4 & 3.4 \\
\hline \multicolumn{5}{|l|}{ Fraction $<60 \mu \mathrm{m}$} \\
\hline $\mathrm{r}$ & 0.919 & 0.937 & 0.789 & 0.900 \\
\hline$s(100 \%) / s(0 \%)$ & $>20$ & 15 & 9.0 & 3.7 \\
\hline
\end{tabular}


uncertainties. With respect to grain-size normalization, application of reference materials for "reference elements", such as $\mathrm{Cs}, \mathrm{Sc}, \mathrm{Fe}, \mathrm{Rb}, \mathrm{Li}$ and $\mathrm{Al}$ (reflecting clayey material content), would be advantageous. Minor uncertainties, which will not affect the general applicability of the present approach, could arise from variations of typical matrix constituents and can be narrowed down by analyzing parameters such as organic matter, carbonate and iron oxide contents.

\subsection{Monitoring biological/chemical sediment quality ("life support")}

Monitoring is a "continuous standard measurement and observation" [67]; the primary objective is to measure the cultural impact on water quality and the suitability of water quality for future use [68]. Among the aims of sediment studies (Section 3), major emphasis will be given to the "establishment of references", "identification of time changes" and "calculation of mass balances". The central aspect is bioavailability, a complex result of contaminant/particle interaction and superimposed by the activity of organisms.

The chemical parameters, which are included in the physico-chemical part of the Triad approach (see Section 2.1) in many countries, are (e.g., The Netherlands [8]: mineral oil; chlorobenzenes; organochlorine pesticides; PCBs (polychlorinated biphenyls) [standard group of 7 congeners]; PAHs (polyaromatic hydrocarbons) [16 of the US Environmental Protection Agency]; and, the heavy metals $\mathrm{Cd}, \mathrm{Cr}, \mathrm{Cu}, \mathrm{Ni}, \mathrm{Pb}, \mathrm{Hg}$, $\mathrm{Zn}$ and As). The concentrations are normalized to values for sediment with a standard granular composition and organic carbon content; in The Netherlands, "standard sediment" is defined as having a $25 \%$ particle fraction $<2 \mu \mathrm{m}$ and $10 \%$ organic matter on a dry weight basis.

A basin-scale assessment involves the balancing of a Conceptual Basin Model (CBM, which considers the mass flows of particles and contaminants, screening level assessment of sediment quality and archived data; see extension in Section 7.3) and basin-scale objectives; with respect to the latter, the WFD mandates "Good ecological status of water bodies" and the Habitats Directive mandates that there is a "Duty to demonstrate no harm" [10]. Both Directives primarily require biological effects-based sediment monitoring and risk assessment for European waters [8].

\subsubsection{Traceability}

7.2.1.1. Unbroken/broken chain of comparison. Standing alone and for an individual sample, the physico-chemical proportion of the Triad does not seem to involve major practical problems. "Sampling", "sample preparation" (using wet sediment) and "chemical analysis" (use of bulk or fractionated reference material; normalization to grain size and organic carbon) widely follows a standard sequence similar to the surveillance approach described in section 7.1. However, with a differentiated approach (e.g., when applying the BCR fractionation scheme (next paragraph)), the question of how to preserve the original physico-chemical forms of both matrices and critical contaminants becomes crucial. This question also relates to the way and the extent to which the findings within the chemical proportion can be compared with the results of the biological studies.

7.2.1.2. Harmonized leaching scheme and CRMs. Interpretation of biological effects is generally facilitated by a more differentiated chemical approach, using BCR fractionation schemes and CRMs of sediment-associated pollutants (Section 6). However, changes in the forms of major, minor and trace constituents cannot be excluded when the sediment is transferred from its typical anoxic environment to chemical analysis via normal sample preparation. Whereas the systematic studies to assess the sources of uncertainties during the certification process of the lake sediments BCR CRM 601 and BCR CRM 701 (Section 6.1) did not indicate major variations within the individual fractions [59], earlier findings of Kersten and Förstner [70] in a less-buffered anoxic mud from Hamburg Harbor demonstrated characteristic shifts of $\mathrm{Cd}$ fractions from 98\% sulfidic/ organic in the control, as received under oxygen-free conditions, to $30 \%$ in the air-dried sample after treatment with elutriate test, and to $15 \%$ in the over dried $\left(60^{\circ} \mathrm{C}\right)$ sample; in the latter sample, more than $30 \%$ of the $31.8 \mathrm{ppm} \mathrm{Cd}$ was found in the exchangeable fraction (extraction scheme [71]), i.e., in an easily bioavailable form.

7.2.1.3. Uncertainties. The gaps between the sedimentchemical part and the biological approaches in the Triad are still enormous, and extension to a river-basin scale will induce further uncertainties. Regarding the wide range of factors influencing uptake and toxicity of contaminants in organisms, it is unlikely that chemical extraction methods will be developed to imitate an allencompassing bioavailability [72].

There are new, sophisticated approaches that can characterize the bioavailability of contaminants and they may construct lines of evidence between contamination and effects on organisms living in the sediment [8,73]. These are at first simple resin extraction methods (e.g., use of Tenax) to determine the availability of sediment-sorbed organic compounds [74]. Another way to bridge the gap between chemistry and ecotoxicology is to treat contaminated sediments with resins to reduce the contaminants to non-toxic levels and to analyze the resins chemically in order to identify the pollutants affecting the organisms 
[75]. However, even with a limited number of pollutants, this approach is still too expensive for routine monitoring. River-basin-wide monitoring, as mandated by the WFD, needs sediment-specific screening methods for both chemical and ecological sampling/ analysis.

A question still open relates to the inclusion of porewater measurements in toxicity testing, and recommendations from a SETAC workshop ([27], see also Section 3.1.4.) are, among others:

- pore-water tests were considered suitable for several types of regulatory frameworks, but unsuitable for others (e.g., as stand-alone pass/ fail methods, or as a substitute for a solid phase test);

- the incorporation of pore-water toxicity test results into empirically-derived sediment quality guidelines (SQGs) might generate guidelines that are more predictive of pore-water effects, better explain the results of pore-water tests, and might be more protective if the pore-water toxicity tests were to pick up a biological response to a chemical or class of chemicals that was missed by the solid-phase testing.

\subsection{Prognoses for remobilization risks ("secondary sources")}

Because of their particular dynamics, two characteristic features of sedimentary and erosive processes in rivers should receive special attention:

(i) the dramatic effects of storm-water events on particle transport; and,

(ii) the rapid and far-reaching effects of chemical changes, in particular, sulfide oxidation.

The respective objectives of this research fall under the category "process studies" (section 3), usually involving a relative high degree of complexity.

\subsubsection{Comparative investigations}

7.3.1.1. Erosion risks. Sediment physical parameters and techniques form the basis of any risk assessment in this field [76]. However, approaches to sediment quality should include experimental designs for the study of chemical and biological effects during erosion and deposition (Section 2.2). For example, in an experimental device developed by Haag et al. [77], sediment cores are moved upwards into a straight, rectangular, pressure duct, which allows measurement of the critical shear stress of erosion as a function of sediment depth. Parallel to hydraulic stability, the depth-dependent sediment samples can be analyzed with respect to chemical and ecological risk assessment.
Typical areas of concern are flood plains, and typical issues are in the context of perturbations, such as wetting-desiccation, as a result of an increase in the frequency of flooding because of climate change [5]; this also involves research on ageing and the natural recovery potential of contaminated sediments (section 2.3).

With respect to the development of a CBM, chemical and ecological information needs a strong basis of data on the quantity of sediment. In a dynamic system, this assessment should include not just those materials that are currently sediments, but also materials, such as soils and mine tailings, that can reasonably be expected to become part of the sediment cycle during the lifetime of a management approach [10].

7.3.1.2. Chemical mobilization risks. Study of variations in sediment and water chemistry should mainly include changes in $\mathrm{pH}$ and redox conditions, competition of dissolved ions and processes such as complexation by organic substances (e.g., metal sulfides have an extremely low solubility and concentrations of metals in pore waters of sediments are generally low). However, an increase in the redox will cause metal sulfides to become unstable. This change is not gradual but rather sudden and an example of a non-linear response [78]. It occurs when polluted (anoxic) sediments are dredged from harbors and dumped either on land or in waterways.

Metal release from tidal Elbe river sediments by a process of "oxidative remobilization" has been described by Kersten ([79], Fig. 4). Short $(30 \mathrm{~cm})$ sediment cores were taken from a site where diurnal inundation of finegrained fluvial deposits takes place. In the upper part of the sediment column, total particulate cadmium content was significantly lower than in the deeper anoxic zone. Sequential extractions using an inert Ar-gas atmosphere in a glove box indicated that, in the anoxic zone, Cd was most associated with the sulfidic/organic fraction, while, in the upper-oxic and transitionzone, the association of $\mathrm{Cd}$ with the carbonatic and exchangeable fractions was typically increased. It is only in this oxic and transition zone that cadmium could be detected in the pore-water samples.

\subsubsection{Traceability}

7.3.2.1. Unbroken/broken chain of comparison. For both erosion risk (I) and chemical mobilization risk studies (II), the chains of comparison are broken at early stages of sampling and sample preparation.

Sampling of flood plain soils and sediments is affected by strong granulometric and compositional heterogeneities arising from the wide spectrum of flow velocities at which the sediments were eroded, transported and deposited. These heterogeneities can be reduced by 


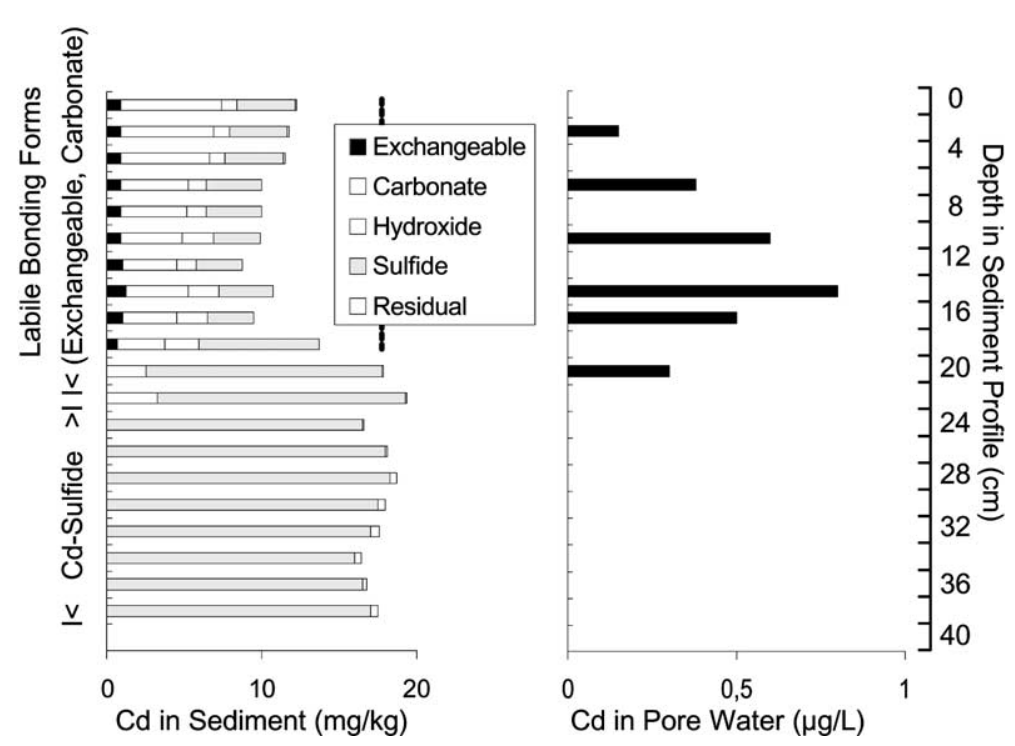

Figure 4. Total concentrations and partitioning of $\mathrm{Cd}$ [71] in a tidal flat sediment profile in the Heuckenlock areas, near Hamburg. Sedimentation rates were determined by the ${ }^{137}$ Cs-method. Cadmium pore-water profile was determined at low tide [79].

subsequent normalization procedures (section 7.1); however, the overall comparability of the samples will be significantly lower than in the applications described in Sections 7.1. and 7.2. for surveillance and monitoring tasks, respectively.

Sampling and sample preparation of in situ sediments primarily has to avoid any modification of labile phases, in particular access of oxygen, which will inevitably change redox-sensitive minerals, such as metal sulfides (see above).

\subsubsection{Reference materials.}

(i) Sediment reference materials should be applied for erosion risk studies in a way similar to that described in Section 7.1 ("surveillance investigations"). Harmonized fractionation schemes and respective reference materials can be useful for studying ecotoxicological aspects, i.e. in the framework of comparative investigations of erosion stabilities and bioavailability of pollutants in sediment core samples, as described in Section 7.3.1 (above).

(ii) Regarding chemical mobilization studies, fractionated reference sediments (even if the chain of direct comparability has been broken) may offer some advantages in providing secondary information on the contents of calcium, iron and sulfur, from which the matrix parameters (capacity-controlling properties), such as "acid producing potential" and "acid consuming capacity", can be calculated and predicted (Section 5.3). These data can also be used in models and, in this way, sequential extractions can serve as effective conformational tools to reduce the complexity of the natural system [80].

Lack of pore-water reference material is a significant deficiency with respect to chemical mobilization studies; because of its specific composition, particularly the high contents of DOC, interstitial water cannot be replaced by conventional surface water reference materials.

7.3.2.3. Uncertainties. regarding the interpretation of findings both from erosion risk (I) and chemical mobilization studies (II) mainly arise from the fact that the reliability of trace-metal analysis proper is masked by large variabilities of influencing factors such as:

(i) granulometric and compositional heterogeneities; erosion experiments involve a wide spectrum of parameters (Fig. 1, Section 2.2) and transfer of laboratory data into the field is still not at a routine level; and,

(ii) anoxic sediment/pore-water extraction and preservation is still difficult (sections 3.1.4, 7.2); the inclusion of capacity controlling properties is not yet part of a standard procedure.

Evaluation of erosion risks on a river-basin scale needs broad information on water and sediment quantities; while the quantification of man-made activities (dredging, reservoir flushing) should be part of advanced watershed management, prediction of the effects of large storm-water events and-even more because of its exponential increase-sediment load are 
Table 4. Development of models coupling hydrodynamic and biogeochemical data for the prediction of pollutant transport in rivers (after Kern [82])

\begin{tabular}{|c|c|c|c|}
\hline Numerical description & Components in water body & Solute-solid interaction & Formulation of transport equation \\
\hline $\begin{array}{l}\text { 1) Distribution coefficient } \\
\left(K_{d} \text {-concept }\right)\end{array}$ & Dissolved + particulate & $\mathrm{K}_{\mathrm{d}}=$ constant & $\begin{array}{l}\text { Two coupled linear differential } \\
\text { equations }\end{array}$ \\
\hline 2) Extended $\mathrm{K}_{\mathrm{d}}$-concept & $\begin{array}{l}\text { Dissolved }+ \text { particulate } \\
+ \text { milieu factors }\end{array}$ & $\begin{array}{l}\mathrm{K}_{\mathrm{d}}=\mathrm{f}(\mathrm{pH}, \mathrm{pe} \text {, complexing agents, } \\
\text { competing ions) }\end{array}$ & $\begin{array}{l}\text { Additional } n \text { linear differential } \\
\text { equations for milieu factors }\end{array}$ \\
\hline $\begin{array}{l}\text { 3) Chemical multi-component } \\
\text { model }\end{array}$ & Individual chemical species & $\begin{array}{l}\text { Dissociation and binding } \\
\text { constants, solubility products }\end{array}$ & $\begin{array}{l}\text { Coupled differential- algebraic } \\
\text { equation system }\end{array}$ \\
\hline $\begin{array}{l}\text { 4) Biochemical multi-component } \\
\text { model }\end{array}$ & Chemical species + biota & Additional growth and decay rates & $\begin{array}{l}\text { Differential algebraic equation } \\
\text { system }\end{array}$ \\
\hline
\end{tabular}

among the most challenging engineering tasks. Similarly, chemical mobilization of pollutants from sediments is a complex, non-linear process, which cannot as yet be modeled in a quantitative way [81].

7.3.2.4. Future developments. Priority research needs relate to the question of how actual and future achievements from chemical and biological sediment studies could be implemented in integrated models (Table 4, after [82]). Today's models for predicting pollutant transport in rivers are dominated by hydromechanical parameters; inclusion of chemical terms mainly means constant distribution coefficients. A first step for extending these models could involve consideration of typical ecosystem factors, such as competing ions, complexing agents, redox conditions and- dominantly for metals- $\mathrm{pH}$ values. The next tier of sophistication would be the inclusion of binding constants, solubility products and other factors, which can describe solid/solution interactions of critical chemicals in a multicomponent system. The last step, as currently foreseeable, would extend the mechanical-chemical model into biology. Such biochemical multi-component models should at least consider rates of growth and decay of organisms and organic matter.

\subsection{Sub-aqueous depots ("final storage")}

Under anoxic, strongly reducing conditions, a great part of the metal content in contaminated sediments is present as practically insoluble sulfides (compared to carbonates, oxides and phosphates). Such conditions can be provided by a permanent water cover, whereby diffusion of oxygen into the sediment is inhibited. However, it has to be taken into consideration that changes in the redox regime can be induced by not only diffusive transport of oxygen through the water-to-sediment interface, but also- and maybe more effectively- bottomdwelling and burrowing organisms creating oxidizing microenvironments. The risk of contaminant uptake by these organisms must thus be ruled out by appropriate cap designs. These combinations of sub-aqueous deposition of contaminated sediments with an adequate capping technology represent attractive remediation alternatives, provided they are technically feasible and do not interfere with national or regional legislation [83].

Two critical interfaces of sub-aqueous depots and their caps have to be carefully studied and long-term environmental safety has to be guaranteed:

1. the hydraulic stability of the depot plus cap and the effectiveretention of pore-water contaminants within the cap during compaction; and,

2. prevention of pollutant transfer from the sediment into the ground water.

Regarding the latter process, considerable information has been assembled in the planning phase and during management of the large "De Slufter" depot, Rotterdam [84]; direct measurements showed that the deposited dredged material has formed a highly impermeable layer, and pollutant transfer is practically limited to very slow diffusion processes [85].

Long-term prognosis of erosion and chemical mobilization risks at the top of the sub-aqueous depots/caps is indispensable to this technology. There is a monitoring program for dredged material capping mainly related to construction, cap performance and management actions [86]. A recent study by Jacobs [87] deals with the monitoring of sub-aqueous depots with active barrier systems for contaminated dredged material using dialysis samplers and diffuse gradients in thin films (DGT) probes. The DGT technique measures effective concentrations at the cap-to-water interface, i.e. a concentration term that comprises the porewater concentration and a release term reflecting the tendency of the cap matrix to release demobilized contaminants.

7.4.1. Traceability. Traceability of pollutant release from sub-aqueous depots is similar to the approach and the results described in Section 7.3 for flood plain or in situ resuspension processes. It can be expected that, after a period of testing on different sites (in The Netherlands, there are already 14 sub-aqueous depots planned or in action [88]), these pore-water techniques can become a standard approach for the assessment of all types of remobilization risks from contaminated in situ sediments. 
Pore-water analytical data can be used in geochemical models for short-, medium- and long-term predictions.

\section{Conclusions}

Chemical analysis of sediments, including suspended particulate matter and pore water, provides efficient tools in water-quality management (surveillance, survey, monitoring); in this context, they refer- in order of increasing complexity- to different objectives, such as preliminary site characterization, identification of chemical anomalies, establishment of references and identification of time changes (chemical, biological), calculation of mass balances, and process studies [21]. Chemical analysis is also used to characterize directly contaminated in situ sediments and dredged materials in relation to various treatment techniques.

In the view of the traceability concept, a "basic sequence" of measurements comprises three steps, which can be considered as an unbroken chain of comparisons (Section 7.1):

1. Sampling and sample preparation (Section 3). Project planning, sampling stations, sampling devices, handling and storage, and $\mathrm{QC}$ are not standardized, but well documented in all aspects [20].

2. Grain size as a characteristic sediment feature (Section 4). Sampling of fine-grained sediment [24] and grain-size normalization with "conservative elements", such as $\mathrm{Cs}, \mathrm{Sc}, \mathrm{Li}$ and $\mathrm{Al}$ (reflecting clayey material content), is recommended as standard approach [31].

3. Analytical. Reference sediment materials are commercially available. While direct species analysis is still limited (Section 5.1), standardized extraction schemes for metals and phosphorus in sediments as well as CRMs for comparisons were developed under the auspices of BCR/IRMM (section 6).

Further steps in chemical sediment analysis are split with regard to specific purposes: sediment quality assessment including biological effects [(4) and (5) below]; coupling of sediment quality data with erosion risk evaluation [(6) and (7) below]; chemical changes following resuspension of anoxic sediments [(8) and (9) below]; and, modeling of chemical sediment data [(10) below].

Sediment quality assessment is part of SSM [1] and should play a significant role in the holistic river-basin approach of the EU's WFD [4]. In recent years, a paradigm shift has taken place to give priority to biological data [8]. The design of a goal-oriented sediment framework [89] recommends, among other, things: (i) ensuring that decision-making is transparent and standardized to some extent, but flexible enough to meet national/regional goals;

(ii) building both natural and regional background concentrations, reference sites and site-specific bioavailability considerations into the framework; and,

(iii) that, while sediment guidelines have an important role, they should not be used as pass/fail values-but rather as triggers for further investigations [91].

Chemical sediment analysis for monitoring studies is usually combined with biological investigations and could be supported by pore-water analysis:

4. Biological/chemical approach. In a comprehensive sediment-assessment approach, five basic components should be considered [6]:

(i) benthic community structure;

(ii) laboratory bioassays for evaluating the toxicity of in-place pollutants;

(iii) bioaccumulation information;

(iv) knowledge of site stability; and,

(v) physico-chemical sediment properties (Section 2.1).

Standing alone and for an individual sample, the physico-chemical proportion of the sediment Triad approach (ecotoxicological, ecological, chemical) [7] widely follows the basic sequence given above. If lines of evidence between chemical sediment contamination and effects on organisms living in the sediment need confirmation, one potential option in the future is the use of resins, which specifically sorb labile and bioavailable fractions of contaminants in the sediment sample [73].

5. Pore water. Tests on pore water (interstitial water) were considered suitable for several types of regulatory frameworks, but unsuitable for others (e.g., as stand-alone pass/fail methods or as a substitute for a solid phase test [27]). Determination of chemical concentrations in pore waters is recommended, in addition to the regular contaminant measurements conducted in the whole sediment, as a means of providing information on routes and levels of exposure, aiding the interpretation of test results, and identifying sources of toxicity. Until now, lack of pore-water reference material is a significant deficiency with respect to chemical mobilization studies (see below).

Because of the particular dynamics of fluvial processes, hydraulic parameters, such as the critical shear stress of erosion processes, form the primary input factors for investigating and predicting large-scale disper- 
sion of contaminants in flood plains, dike foreshores and polder areas. Unlike problems related to conventional polluted sites, the risks here are primarily connected with the deposition of contaminated solids on soils in downstream regions. Short-term issues include the fate of sediment-associated contaminants when sediment is deposited upland and a better understanding of the impact on groundwater, water and soil ecoystems. Medium/long-term issues will focus on integration of quality and quantity aspects, and determination of the sediment-transport processes at the riverbasin scale as a function of land and water use and hydrological (climate) change [5].

6. Erosion effects. Sediment physical parameters and techniques form the basis of any risk assessment in this field. Sampling of flood plain soils and sediments is affected by strong granulometric and compositional heterogeneities arising from the wide spectrum of flow velocities at which the sediments were eroded, transported and deposited. Standardized fractionation schemes and respective reference materials can be useful for studying ecotoxicological aspects of resuspended sediments (Section 7.3). Sediment quality issues should include experimental designs for the study of chemical and biological effects during erosion and deposition [75]. Coupling of erosion experiments with investigations of ageing effects as well as of the mobilization of chemicals from pore-water and labile sediment phases (below) could provide a valuable tool in the decision-making process for remediation techniques.

7. Ageing effects. "Diagenetic" effects, which, apart from chemical processes (sorption, precipitation, occlusion, incorporation in reservoir minerals and other geosorbents such as char, soot and ashes), involve enhanced mechanical consolidation of soil and sediment components by compaction, loss of water and mineral precipitations in the pore space, may induce a quite essential reduction in the reactivity of solid matrices. The methodologies developed so far [16-19] could influence the traceability aspects in the field of ecological/chemical risk assessment (Section 7.2) and in relation to erosion stability/pollutant mobility both in situ and river-basin wide (Section 7.3), and they will also affect the decision-making process for remediation techniques (Section 7.4).

The dramatic effects of storm-water events on particle transport can coincide with rapid and far-reaching chemical changes, in particular, by the effects of sulfide oxidation on the mobilization of toxic metals. The objectives of this research fall under the category "process studies", usually involving a relatively high degree of complexity. Such field and laboratory studies, as well as the models using these data, are indispensable for long-term prognosis of erosion and chemical mobilization risks arising from sub-aqueous deposition and capping, both favorable technologies for dredged material and in situ sediments [2].

8. Anoxic/oxidized samples. Changes of the forms of major, minor and trace constituents cannot be excluded, when the sediment is transferred from its typical anoxic environment to chemical analysis via normal sample preparation. However, a comparison of extraction data from original and oxidized samples could be used for worst-case considerations in respect to potential metal release during sediment resuspension (Section 7.3) or subsequent to upland deposition of dredged material (Section 7.4).

9. Capacity controlling properties. Both $\mathrm{pH}$ and redox potential in sediment/water systems are significant parameters for mobilization and transformation of metals or phosphorus. Criteria for prognosis of the middle- and long-term behavior of these and other substances should, therefore, include the abilities of sediment matrices to produce acidity and to neutralize such acid constituents. In section 5.3, an example was given to indicate how simultaneous application of standard sequential leaching techniques on critical metals and matrix components can be used for the characterization of anoxic, sulfide-bearing sediments in relation to the mobility of these metals [50].

10. Modeling. The data for critical trace metals and matrix components, as determined from original samples [see topic (8) above], can also be used in models and, in this way, sequential extractions can serve as effective conformational tools to reduce the complexity of the natural system [80]. Pore-water analytical data can be applied in geochemical models for short-, medium- and long-term predictions [90]. Transport and reaction models consider advective, dispersive and diffusive transport mechanisms as well as adsoption and desorption processes [91]

A basin-scale assessment involves the balancing of a CBM, which considers the mass flows of particles and contaminants, screening level assessment of sediment quality and archived data [10]. Coupling quality and quantity data involves models at different scales [9]:

(i) hydrodynamic models operating on the particle 
level are best suited to the study of fine-scale aggregation/segregation processes;

(ii) continuum-mechanical field models as well as particle-tracking models are particularly efficient at locally concentrated emissions; and,

(iii) macroscale long-term simulation can only be performed using simplified models, because of the limited computer capacity available so far.

In total, the traceability of the "further steps" [(4)(10) above] is less pronounced than that of the three steps [(1)-(3) above] of the "basic sequence". However, in the light of the economic value of these further steps for developing and executing far-reaching management plans, coordinated efforts should be undertaken to improve this situation. Short-term measures should range from the organized dissemination of results from on-going research ("ageing effects"), official documentation of techniques and instruments in a relative new field ("erosion effects") and state-of-the-art procedures ("modeling", e.g. analytical data from pore water), via extension of standardized extraction schemes and reference materials (prescription for handling "anoxic sediments" for fractionation, certification of specific constituents, such as $\mathrm{Ca}, \mathrm{S}$ and $\mathrm{Fe}$ (II) for the study of "capacity-controlling properties"), up to the development of new reference materials ("pore water"). With regard to the quantitative aspect of contaminated sediments at the river-basin scale, chemical inventories of interim deposits, such as mining residues, river bank, polder and flood plain deposits, fillings of river dams and lock reservoirs, should be given high priority.

\section{References}

[1] The SedNet Strategy Paper, SedNet- Demand Driven, European Sediment Research Network- Proposal No. EVK-2001-00058 to EU Key Action 1 "Sustainable Management and Quality of Water", 1.4.1 "Abatement of water pollution from contaminated land, landfills and sediments" (1/2002-12/2004), draft, June 2003.

[2] U. Förstner, Environ. Sci. Pollut. Res. 10 (2003) 58.

[3] W.M. Stigliani, Environ. Monit. Assess 10 (1988) 245.

[4] U. Förstner, J. Soils Sediments 2 (2002) 54.

[5] J. Brils, W. Salomons, J. van Veen (Editors), SedNet Recommendations for Research Priorities Related to Sediment, 9 pp. November 2003 (in [1]).

[6] G. Krantzberg, J.H. Hartig, M.A. Zarull, Environ. Sci. Technol. $34(2000) 22$, A.

[7] P.M. Chapman, Ecotoxicology 5 (1996) 327.

[8] P.J. den Besten, E. de Deckere, M.P. Babut, B. Power, T.A. DelValls, C. Zago, A.M.P. Oen, S. Heise, J. Soils Sediments $3(2003) 144$.

[9] U. Förstner, J. Soils Sediments 1 (2001) 111.

[10] S. Apitz, S. White, J. Soils Sediments 3 (2003) 132.

[11] P.B. Hatzinger, M. Alexander, Environ. Sci. Technol. 29 (1995) 537.

[12] R.G. Luthy, G.R. Aiken, M.L. Brusseau, S.D. Cunningham,
P.M. Gschwend, J.J. Pignatello, M. Reinhard, S.J. Traina, W.R. Weber Jr., J.C. Westall, Environ. Sci. Technol. 31 (1997) 3341.

[13] U. Förstner, J. Gerth, in: R. Stegmann, G. Brunner, W. Calmano, G. Matz (Editors) Treatment of Contaminated Soils, Springer, Berlin, Germany, 2001, pp. 567-586.

[14] W. Chen, A.T. Kan, M.B. Tomson, Environ. Sci. Technol. 34 (2000) 385.

[15] M. Alexander, Environ. Sci. Technol. 34 (2000) 4259.

[16] E.M.J. Verbruggen, W.H.J. Vaes, T.F.Parkerton, J.L.M. Hermens, Environ. Sci. Technol. 34 (2000) 324

[17] H.A. Thompson, G.A. Parks, G.E. Brown Jr., Geochim. Cosmochim. Acta 63 (1999) 1767.

[18] P. Corbisier, D. van der Lelie, B. Borremans, A. Provoost, V. de Lorenzo, N. Brown, J. Lloyd, J. Hobman, E. Csöregi, G. Johannsson, B. Mattiasson, Anal. Chim. Acta 387 (1999) 235.

[19] H. Zhang, F.-J. Zhao, B. Sun, W. Davison, S.P. McGrath, Environ. Sci. Technol. 35 (2001) 2602.

[20] A. Mudroch, J.M. Azcue, Manual of Aquatic Sediment Sampling, Lewis Publishers, Boca Raton, FL, USA, 1995.

[21] H.L. Golterman, P.G. Sly, R.L. Thomas, Study of the Relationship Between Water Quality and Sediment Transport. Technical Papers, in: Hydrology No. 26, UNESCO, Paris, France, 1983.

[22] L. Hakanson, M. Jansson, Principles of Lake Sedimentology, Springer, Berlin, Germany, 1983.

[23] R. Baudo, in: R. Baudo, J. Giesy, H. Muntau (Editors), Sediments: Chemistry and Toxicity of In-Place Pollutants, Lewis Publishers, Chelsea, Michigan, USA, 1990, pp. 15-60.

[24] A. Horowitz, A Primer on Sediment-Trace Element Chemistry, 2nd ed, Lewis Publishers, Chelsea, Michigan, USA, 1991.

[25] A. Mudroch, S.D. MacKnight, Techniques for Aquatic Sediment Sampling, 2nd ed, Publishers, Boca Raton, FL, USA, 1994.

[26] A. Mudroch, S.D. MacKnight, in: [25], pp. 5-16.

[27] R.S. Carr, M. Nipper (Editors), Summary of a SETAC Technical Workshop "Pore water Toxicity Testing: Biological, Chemical, and Ecological Considerations with a Review of Methods and Applications, and Recommendations for Future Areas of Research", SETAC, Pensacola, FL, USA, 2001.

[28] A. Mudroch, R.A. Bourbonniere, in: [25] pp. 29-96.

[29] M. Kersten, U. Förstner, Mar. Chem. 22 (1987) 299.

[30] L. Keith, Environmental Sampling and Analyses: A Practical Guide, Lewis Publishers, Chelsea, Michigan, USA, 1991.

[31] U. Förstner, Contaminated Sediments, Lecture Notes in Earth Sciences, Springer, Berlin, Germany, 1989.

[32] U. Förstner, W. Salomons, Environ. Technol. Lett. 1 (1980) 494.

[33] F. Ackermann, Environ. Technol. Lett. 1 (1980) 518.

[34] H. Hellmann, Z. Fresenius', Anal. Chem. 316 (1983) 286.

[35] R.L. Thomas, J.-M. Jaquet, A.L.W. Kemp, C.F.M. Lewis, J. Fish. Res. Board Can. 33 (1976) 385.

[36] A.L.W. Kemp, R.L. Thomas, C.I. Dell, J.-M. Jaquet, J. Fish. Res. Board Can. 33 (1976) 440.

[37] A. Horowitz, K. Elrick, in: J. Lichtenberg et al. (Editors), Chemical and Biological Characterization of Sludges, Sediments, Dredge Spoils, and Drilling Muds, ASTM STP 976, Philadelphia, PA, USA, 1988.

[38] G.E.J. Brown, A.L. Foster, J.D. Ostergren, Proc. Natl. Acad. Sci. U.S.A. 96 (1999) 3388.

[39] D.G. Schulze, P.M. Bertsch, in: D.L. Sparks (Editor), Advances in Agronomy, Academic Press, New York, USA, 1995, vol. 55, p. 1.

[40] D. Roberts, A.C. Scheinost, D.L. Sparks, in: H.M. Selim, W.L. Kingery (Editors), Geochemical and Hydrological Reactivities of Heavy Metals in Soils, Lewis Publishers, Boca Raton, FL, USA, 2003, pp. 187-227. 
[41] M. Kersten, in H.A. van der Sloot, L. Heasman, Ph. Quevauviller (Editors), Harmonization of Leaching/Extraction Tests, Studies in Environmental Science 70, Elsevier, Amsterdam, The Netherlands, 1997, pp. 75-99.

[42] U. Förstner, in: G. Rauret, Ph. Quevauviller (Editors), Int. J. Environ. Anal. Chem. 51 (1993) 5.

[43] A. Tessier, P.G.C. Campbell, Hydrobiologia 149 (1987) 43.

[44] A.M. Ure, Ph. Quevauviller, H. Muntau, B. Griepink, in: G. Rauret, Ph. Quevauviller (Editors), Int. J. Environ. Anal. Chem. 51 (1993) 135

[45] J. Hong, U. Förstner, W. Calmano, in: J.L. Hamelink, P.F. Landrum, H.L. Bergman, W.H. Benson (Editors), Bioavailability: Physical, Chemical, and Biological Interactions, Lewis Publishers, Boca Raton, FL, USA, 1994, pp. 119-141.

[46] P.H. Rahn, Environ. Geol. Water Sci. 19 (1992) 47.

[47] K.D. Ferguson, P.M. Erickson, in: W. Salomons, U. Förstner (Editors), Environmental Management of Solid Waste. Mine Tailings and Dredged Materials, Springer, Berlin, Germany, 1988, pp. 14-43.

[48] A.A. Sobek, W.A. Schuller, J.R. Freeman, R.M. Smith, Field and Laboratory Methods Applicable to Overburden and Mine Spoils, Report EPA-600/2-78-0523, U.S. Environmental Protection Agency, Washington, DC, USA, 1978.

[49] A. Bruynesteyn, R.P. Hackl, Miner. Environ. 4 (1984) 5.

[50] M. Kersten, U. Förstner, Geomarine Lett. 11 (1991) 184.

[51] H.E. Allen, G. Fu, B. Deng, Environ. Toxicol. Chem. 12 (1993) 1441.

[52] D.M. DiToro, J.D. Mahony, D.J. Hansen, K.J. Scott, M.B. Hicks, S.M. Mayr, M.S. Redmond, Environ. Toxicol. Chem. 9 (1990) 1487.

[53] D.M. DiToro, J.D. Mahony, D.J. Hansen, K.J. Scott, A.R. Carlson, G.T. Ankley, Environ. Sci. Technol. 26 (1990) 96.

[54] D. Hansen, W. Berry, J. Mahony, W. Boothman, D. DiToro, D. Robson, G. Ankley, D. Ma, Q. Yan, C. Pesch, Environ. Toxicol. Chem. 15 (1996) 2080.

[55] J.S. Meyer, W. Davison, B. Sundby, J.T. Oris, D.J. Laurén, U. Förstner, J. Hong, D. Crosby, in: J.L. Hamelink, P.F. Landrum, H.L. Bergman, W.H. Benson (Editors), Bioavailability: Physical, Chemical, and Biological Interactions, Lewis Publishers, Boca Raton, FL, USA, 1994, pp. 155-170.

[56] S.B. Griscom, N.S. Fisher, S.N. Luoma, Environ. Sci. Technol. $34(2000) 91$.

[57] Ph. Quevauviller, Methodologies for Soil and Sediment Fractionation Studies, Royal Society of Chemistry, Cambridge, UK, 2002.

[58] Ph. Quevauviller, in [57], pp. 1-9.

[59] A. Sahuquillo, J.F. Lopéz-Sánchez, G. Rauret, A.M. Ure, H. Muntau, Ph. Quevauviller, in [57], pp. 10-26.

[60] A. Sahuquillo, J.F. Lopéz-Sánchez, R. Rubio, G. Rauret, R.P. Thomas, C.M. Davidson, A.M. Ure, Anal. Chim. Acta 382 (1999) 317.

[61] G. Rauret, J.F. Lopéz-Sánchez, D. Lück, M. Yli-Halla, H. Muntau, Ph. Quevauviller, EUR 19775 EN, Certification Report of BCR 701, European Commission, Brussels, Belgium, 2001.

[62] V. Ruban, J.F. Lopéz-Sánchez, P. Pardo, G. Rauret, H. Muntau, Ph. Quevauviller, in [57], pp. 105-121.

[63] J.D.H. Williams, J.-M. Jaquet, R.L. Thomas, J. Fish. Res. Board Can. 33 (1976) 413.

[64] V. Ruban, G. Rauret, J.F. Lopéz-Sánchez, H. Muntau, Ph. Quevauviller, EUR 19776 EN, Certification Report of BCR684, European Commission, Brussels, Belgium, 2001.

[65] H.E. Hawkes, J.S. Webb, Geochemistry in Mineral Exploration, Harper and Row, New York, USA, 1962.

[66] T.O. Meiggs, in: R.A. Baker (Editor), Contaminants and Sediments, Ann Arbor Science, Ann Arbor, MI, USA, 1980, pp. 297-308.
[67] World Health Organization, Water Quality Survey, A Guide for the Collection and Interpretation of Water Quality Data, Studies and Reports in Hydrology, No. 23, UNESCO, WHO, Paris, France, 1978.

[68] World Health Organization, GEMS: Global Environmental Monitoring System, WHO, Geneva, Switzerland, 1978.

[69] J.N. O'Connor in: Guidelines for Differentiating Anthropogenic from Natural Trace Metal Concentrations in Marine Sediments- Normalization Techniques, ICES-Working Group on Marine Sediments in Relation to Pollution, 20-23 February 1989, Savannah, Georgia, USA, International Council for the Exploration of the Sea (ICES), Copenhagen, Denmark, 1989.

[70] M. Kersten, U. Förstner, in: J.O. Nriagu, J.B. Sprague (Editors), Cadmium in the Aquatic Environment, Wiley, New York, USA, 1987, pp. 51-88.

[71] U. Förstner, W. Calmano, Vom Wasser 59 (1982) 83.

[72] W. Ahlf, U. Förstner, J. Soils Sediments 1 (2001) 30.

[73] G. Cornelissen, H. Rigterink, T.E.M. ten Hulscher, B.A. Vrind, P.C.M. van Noort, Toxicol. Chem. 20 (2001) 706.

[74] R.M. Burgess, M.J. Ahrens, C.W. Hickey, P.J. den Besten, T.E.M. ten Hulscher, B. van Hattum, J.P. Meador, P.E.T. Douben, in: P.E.T. Douben (Editor), PAHs: An Ecological Perspective, Wiley, Chichester, West Sussex, UK, 2003, pp. 99-126.

[75] P.A. Kosian, C.W. West, M.S. Pasha, J.S. Cox, D.R. Mount, R.J. Huggett, G.T. Ankley, Environ. Toxicol. Chem. 18 (1999) 201.

[76] A. Zeman, T. Patterson, in: F.R. Burden, I. McKelvie, U. Förstner, A. Guenther (Editors), Environmental Monitoring Handbook, McGraw-Hill, New York, USA, 2002, Chapter 15.

[77] I. Haag, U. Kern, B. Westrich, Sci. Total Environ. 266 (2001) 249.

[78] W. Salomons, in: W. Salomons, W.M. Stigliani (Editors), Biogeodynamics of Pollutants in Soils and Sediments- Risk Assessment of Delayed and Non-Linear Responses, Springer, Heidelberg, Germany, 1995, pp. 1-30.

[79] M. Kersten, Mechanisms and Balances of Heavy Metal Mobilization from a Freshwater Tidal Flat in the Elbe River (in German), Dissertation, Technical University of HamburgHarburg, 1989.

[80] K. Wallmann, M. Kersten, J. Gruber, U. Förstner, in: G. Rauret, Ph. Quevauviller (Editors), Int. J. Environ. Anal. Chem. 51 (1993) 187.

[81] U. Förstner, in: [76], pp. 247-307.

[82] U. Kern, Transport of Suspended Matter and Contaminants in Lock-Regulated Rivers. Example of Neckar River (in German), Comm. Institute for Hydraulics, University of Stuttgart, No. 93, Stuttgart, Germany, 1997.

[83] U. Förstner, E. Beitinger, F. Tarnowski, M. Gehrke, H. Burmeier, P. Jacobs, in: [76], Chapter 13.

[84] M. Loxham, in: [47], pp. 3-23.

[85] Anon, Consolidation of Dredged Material in the Slufter Depot, Report No. 97-124/C (in Dutch), Gemeentewerken Rotterdam, The Netherlands, 1998.

[86] http://www.epa.gov/grtlakes/sediment/iscmain/five.htlm.

[87] P.H. Jacobs, J. Soils Sediments 3 (2003) 100.

[88] Depotec/Port of Hamburg, Subaquatic Storage of Dredged Material in The Netherlands (in Dutch/German) CD-ROM, Depotec/Port of Hamburg, Hamburg, Germany, 2002.

[89] S.E. Apitz, E.A. Power, J. Soils Sediments 2 (2002) 61.

[90] D.L. Parkhurst, C.A.J. Postma, User's Guide to PHREEQC (Version 2)- A Computer Program for Speciation, Batch-Reaction, One-Dimensional Transport, and Inverse Geochemical Calculations, Water-Resources Investigations Report 994259, U.S. Geol. Surv. Denver, Colorado, USA, 1999.

[91] H. Landenberger, CoTReM- A Multi-component Transport and Reaction Model [in German], Section of Geochemistry and Hydrogeology, University of Bremen, Germany, 1998. 